- neurophysiology at the University of Turin, who will coordinate the neurosciences committee.

Genome research has struggled to gain a toe-hold in Italy. "Italy has been the only one of the G8 countries not to have a genome project, or any serious money for genome research from the state," says Andrea Ballabio, director of the Telethon Institute of Genetics and Medicine in Milan, and a member of the genomics committee, now called the Committee for Medical Genetics.

This concern led Ballabio, along with several other top geneticists and molecular biologists in Italy, to create an informal group called the Genome Task Force. This spent more than a year working in secret to escape external pressures - on a strategy paper for genome research. It had planned to present the paper to the research ministry, when it was overtaken by Sica's initiative.

The paper suggests the creation of national centres to service fields such as genotyping, bioinformatics, expression profiling and proteomics. It also advocates the support of projects to develop animal models for genetic diseases, and to build on strengths in population genetics. This paper is likely to be a springboard for the national committee's discussions.

"The committee is an important first step for us," says Ballabio, "and it is certainly not too late for Italy to catch up — the interesting genome work is only just starting now that the sequences are being completed."

Although the genomics and neurosciences national committees will define broad strategic goals, they will not control the distribution of grant money. This will be based on the advice of a panel of international experts.

Sica, a neuropathologist from the University of Naples, was appointed undersecretary of state for research last December. Knowing that his time in office would be short - government collapses notwithstanding, general elections are due in Italy next year - he has concentrated on

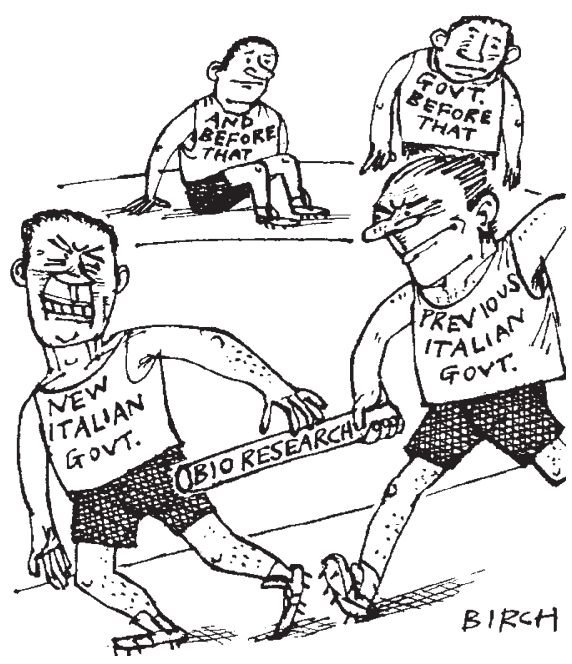

pushing through initiatives in what he believes to be the two most important research areas. Many of the scientists on the two committees feel that Sica's initiative would almost certainly have evaporated had he not been reappointed. Alison Abbott

\title{
Israel debates raising commitment to CERN
}

\section{Jerusalem}

Keen to boost its role in the European scientific community, Israel's science ministry is considering whether to apply for full membership of the European Laboratory for Particle Physics (CERN). But although some Israeli physicists are enthusiastic, others worry about the the financial and scientific implications.

The 1992 agreement granting Israel observer status, similar to other countries such as the United States, Japan and Russia, is about to expire. Under this agreement, Israel pays 20 per cent of full membership dues - about 2 million Swiss francs (US\$1.2 million) a year. In exchange, Israeli researchers and postdocs can participate in CERN research programmes, and Israeli companies can bid for CERN tenders.

Renewal of observer status seems the most likely short-term outcome. But some Israeli particle physicists are pushing hard for full membership. The reasons, they admit, are as much political as scientific.

"Israel is no longer a Third World country. It has to take responsibility for the things that large countries do. It has to support first-class science," says Giora Mikenberg, professor of particle physics at the Weizmann Institute of Science.

Mikenberg, who leads the muon project at CERN's Large Hadron Collider, thinks that membership of CERN could lead to Israel becoming a full partner in other European scientific programmes - such as the European Space Agency - and

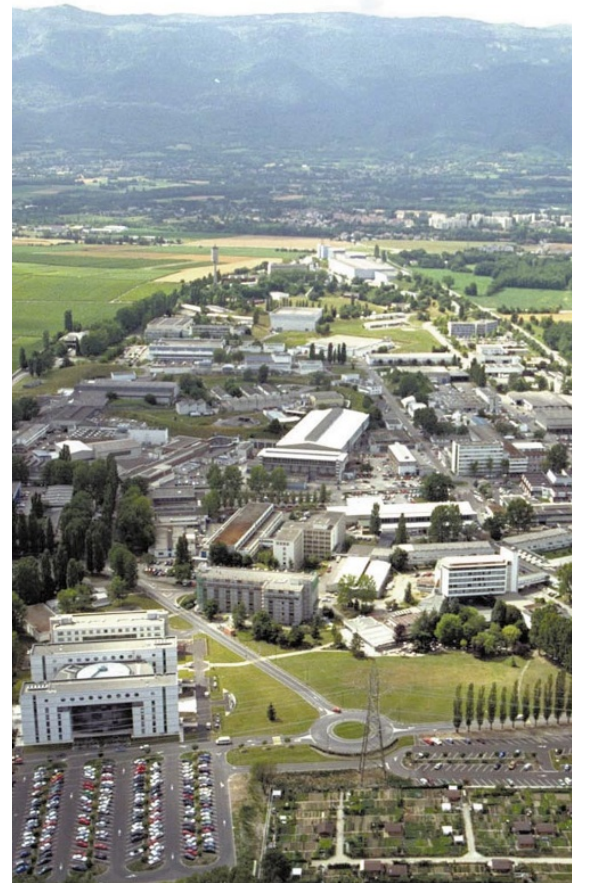

Collision course: Israeli physicists are divided over the benefits of full membership of CERN.

would show that Israel was a scientific power of the first rank. Full membership would also allow Israelis to be CERN employees and to participate in scientific decision-making there.

The main problem, Mikenberg acknowledges, is the price tag. The ministries of science and industry, which fund Israel's observer status at CERN, will not be able to finance full membership, meaning that the cabinet would have to allocate money from the national treasury, he says.

Israeli minister of science Matan Vilnai visited CERN recently and was impressed by what he saw. An informal ministry forum of industrialists, researchers and government officials has discussed full membership and made a favourable recommendation to Vilnai.

Sources in the ministry claim that Vilnai discussed the possibility of full membership with CERN officials. But CERN directorgeneral Luciano Maiani denies having any conversations about the matter with Vilnai or anyone else. "The issue is not on the agenda," he insists. "There is no official move in that direction."

Other Israeli physicists are doubtful about the scientific benefits of full membership, and worry that it might actually have negative consequences. Shmuel Nussinov, a theoretical physicist at Tel Aviv University, says that he would welcome closer ties with CERN, but worries that the additional funding needed might come at the expense of existing research.

Another physicist says that, at present, Israeli physicists can participate in CERN research projects but have other options. Full membership of CERN could mean putting all the country's eggs in one basket, he says, and might make it harder for Israelis to find funding to take part in particle-physics research elsewhere.

Haim Watzman 